\title{
Análise do Impacto das Campanhas Educativas na Temática do Suicídio Sobre os Acadêmicos dos Cursos de Medicina, Psicologia e Licenciaturas
}

\section{Analysis of the Impact of Educational Campaigns on the Suicide Theme on the Students of Medicine, Psychology and Teaching Certification Courses}

\author{
Matheus Marques da Silva Santos ; Juliana Massambani Aleixo Silva ${ }^{\mathrm{a}}$; João Matheus Albertoni Macedo ${ }^{\mathrm{b}}$; Antonio Sales*b \\ aUniversidade Anhanguera Uniderp, Curso de Medicina. MT, Brasil. \\ ${ }^{b}$ Universidade Anhanguera Uniderp, Programa de Pós-Graduação Stricto Sensu em Ensino de Ciências e Matemática. MT, Brasil. \\ *E-mail: profesales@hotmail.com
}

\begin{abstract}
Resumo
O presente trabalho é produto de uma pesquisa quantitativa descritiva, tendo acadêmicos de Medicina, Psicologia, Pedagogia, Serviço Social e Matemática, de uma única Instituição de Ensino Superior, como participantes. O tema abordado foi sobre as campanhas educativas que orientam sobre o trato com pessoas com tendência suicida. A escolha desses cursos ocorreu pelo fato de prepararem profissionais para tratarem diretamente com pessoas de diversas idades e classes sociais. A proposta foi feita por um acadêmico de Medicina e conduzida por ele em parceria com uma colega de turma e um mestrando. O objetivo foi avaliar o impacto de uma campanha educativa. Foram abordados, direta e indiretamente, 136 acadêmico(a)s por meio de um formulário, com 16 questões, elaborado no Google forms. Para os acadêmicos de Medicina, que já estavam no internato, foi enviado o link pelo celular e, para os demais, foi entregue impresso enquanto estavam em sala de aula. $\mathrm{O}$ acesso foi reduzido por causa do COVID19 que limitou o contato. Os resultados apontam que, até o momento, a campanha ainda não produziu os resultados esperados e que o enfoque deve ser na orientação de como agir, com indicações de locais para os quais poderão encaminhar, e não apenas na informação sobre o comportamento da pessoa.
\end{abstract}

Palavras-chave: Comportamento Suicida. Sofrimento do Suicida. Trato com o Suicida.

\begin{abstract}
The present work is the product of a quantitative descriptive research with students from Medicine, Psychology, Pedagogy, Social Work and Mathematics, from a single institution of higher education, as participants. The topic approached was about the educational campaigns that guide about dealing with people with a suicidal tendency. The choice of these courses was because they prepare professionals to deal directly with people of different ages and social classes. The proposal was done by a medicine school student and conducted by him or her in partnership with a classmate and a master's student. The main objective was to evaluate the impact of an educational campaign. 136 students were addressed directly and indirectly through a form, with 16 questions, elaborated in Google forms. For medicine school students, who were already in internship, the link was sent by cell phone and, for the others, it was handed out printed while they were in class. Access was reduced because of COVID19, which limited contact. The results show that, so far, the campaign has not produced the expected results yet and that the focus should be on orienting how to act, with indications of where they can go, and not just on information about the person's behavior.
\end{abstract}

Keywords: Suicidal Behavior. Suffering of the Suicide Victim. Dealing with the Suicide Victim

\section{Introdução}

O termo suicídio se refere a um ato autorreflexivo fatal praticado intencional e conscientemente pela pessoa que deseja morrer (CFM; ABP, 2014; SADOCK; SADOCK; RUIZ, 2017). Segundo a Organização Mundial de Saúde - OMS, o suicídio é a $15^{\mathrm{a}}$ causa de óbito na população geral (BRASIL, 2017). As maiores taxas de suicídio em homens ocorrem na região da Europa, enquanto em mulheres no Sudeste Asiático. Em relação à faixa etária, independente do sexo, a maior taxa de suicídio se concentra a partir dos 70 anos. Nos indivíduos do sexo masculino, existe uma relação proporcional do crescimento da taxa de suicídio e o envelhecimento. Por sua vez, no sexo feminino, ocorreu também uma elevação dessa taxa com o aumento da idade, porém com um brusco pico entre 15-29 anos e um decréscimo entre 30-49 anos, a partir de então retomou o crescimento e atingiu seu máximo índice de suicídio nas mulheres com 70 anos ou mais. Mundialmente, no que tange ao sexo, a taxa de mortalidade por suicídio foi duas vezes mais elevado nos homens em comparação com as mulheres em 2016 (WHO, 2019).

Esses dados permitem o dimensionamento da relevância da abordagem da temática do suicídio, cuja intenção final é estimular boas práticas de saúde pública. Para tanto, é importante que se transmita informações precisas, consistentes, verídicas e de fácil compreensão sobre as expressões que englobam a ideação e comportamento suicida, a fim de que seja adotada uma abordagem do indivíduo em risco de suicídio (SADOCK; SADOCK; RUIZ, 2017).

A ideação suicida é o pensamento de se tornar o agente indutor de sua própria morte. No plano das ideias, portanto, o indivíduo se torna capaz de pensar na morte como estratégia 
de alívio, porém sem cogitar em sua autoprovocação. Nessa perspectiva, a morte é uma alternativa desejada, porém sem planejamento de execução. Com agravamento da situação, o indivíduo passa pela fase do planejamento quanto ao método, dia e até ao horário para a execução do plano (MELEIRO; MELO; WANG, 2007).

Ainda, no contexto das ideias, pode-se destacar o ideal de letalidade suicida como uma designação de periculosidade. Tal expectativa, apesar de nem sempre coincidir com potencial de letalidade do meio utilizado, não desmerece a atenção que se deve dar a esses casos, uma vez que o mesmo sendo o método ineficaz, a intenção do paciente era real. Nesse contexto, emerge a intenção suicida, uma expectativa subjetiva, que classifica o ato autodestrutivo como fator de gatilho para a morte (SADOCK; SADOCK; RUIZ, 2017).

Ultrapassando o plano das ideias, o sujeito em tendência suicida pode executar ou não sua programação. No último caso, a interrupção de comportamento que apresente um potencial autodestrutivo antes de danos físicos acompanhado de sinais de que o indivíduo pretendia provocar sua própria morte é denominado de tentativa de suicídio abortada (SADOCK; SADOCK; RUIZ, 2017).

Em outros casos, por sua vez, pode não ocorrer a interrupção dos atos autodestrutivos. A automutilação deliberada se insere, nesse contexto, e se refere a atos intencionais, que promovam dor, lesão ou destruição, porém sem a finalidade de cometer suicídio. Contraposto a isso, insere-se a tentativa de suicídio, situação esta em que o indivíduo apresentou comportamento autodestrutivo não fatal, mas com finalidade de suicida. Isso demonstra, portanto, o insucesso do objetivo do indivíduo. Nas situações, porém, em que a finalidade suicida é alcançada, define-se o suicídio (SADOCK; SADOCK; RUIZ, 2017).

A identificação da funcionalidade de campanhas de prevenção ao suicídio é manifestada por meio da capacidade das pessoas de detectarem algum padrão, que sugestione possível risco de suicídio, seguido da promoção do cuidado. Tal temática é de extrema importância que seja abordada dentro da sala de aula, visto que é o ambiente no qual estão presentes possíveis futuros profissionais que lidarão, diretamente, com situações, em que será necessária a aplicação do conhecimento abordado nessas campanhas.

Nesse contexto, este trabalho tem por objetivo analisar a influência das campanhas educativas sobre acadêmicos dos cursos de Medicina, Psicologia, Matemática, Pedagogia e Serviço Social do campus matriz da Universidade AnhangueraUniderp sobre o trato com pessoas em ideação suicida.

\section{Material e Métodos}

A pesquisa se insere na perspectiva quantitativa descritiva, não probabilística. O processo consistiu em um formulário que foi entregue para o acadêmico preencher e, posteriormente, foi analisado à luz da Estatística Descritiva.

O projeto de pesquisa foi aprovado pelo Comitê de
Ética - CEP/ Uniderp, com o número de registro CAAE: 19948719.2.0000.5161, pois apresentava o risco de constrangimento ao participante diante da possibilidade de ter que admitir desconhecimento sobre o conteúdo das perguntas. Para evitar qualquer tipo de constrangimento, cada um dos participantes assinou o Termo de Consentimento Livre e Esclarecido (TCLE), conforme Resolução 466/2012 CNS, do Ministério da Saúde (BRASIL, 2013), que continha um item informando que por ser um assunto que só recentemente está em pauta de divulgação, é possível que haja desconhecimento de alguma característica da pessoa com ideação suicida. Nesse caso, o participante pôde deixar a questão em branco ou simplesmente marcar que está em dúvida, que é uma das opções de resposta.

A coleta de dados foi realizada por acadêmicos de Medicina, que apresentaram os formulários aos participantes, composto por dezesseis questões, seguidos dos critérios de inclusão: ser acadêmico do segundo ao último semestre dos cursos de Medicina, Psicologia, Matemática, Pedagogia e Serviço social da Universidade Anhanguera - Uniderp. Já os critérios de exclusão foram: não concordar em participar e ser menor de 18 anos.

Os acadêmicos e profissionais dos cursos de Matemática e Pedagogia estão em contato com adolescentes e jovens, no ambiente escolar, e de acordo com Prado e Pinto (2019), os professores possuem uma convivência e comunicação com os alunos, que em alguns casos apresentam tendências suicidas, portanto, importante o professor estar bem informado para lidar com situações, que podem gerar momentos de risco à vida. Desse modo, é necessário que o professor possua informações, que possam orientar uma conduta que promova a segurança e o bem-estar no ambiente educacional.

Os profissionais do Serviço Social também possuem contato com a sociedade de modo geral, seja nas escolas, nos hospitais, nos departamentos de justiça, nas organizações não governamentais entre outras áreas, dessa forma StavizkiJunior e Viccari (2018) descrevem que o assistente social possui um papel importante em questões relacionadas ao suicídio, seja com os indivíduos com comportamento suicida ou com os profissionais da saúde, que atendem as demandas de tentativas e com casos confirmados/consumados, pois procuram desenvolver respostas em tempo reduzido com o intuito de auxiliar em casos de urgência.

Já os acadêmicos e profissionais da saúde como Médicos e Psicólogos atuam de maneira direta em programas ou atendimentos a pessoas com tendência suicida, pois recebem uma capacitação para lidar com este tema desde a formação acadêmica. Desse modo, Santos e Kind (2020) afirmam que profissionais, de diversas áreas, devem trabalhar o tema sobre suicídio, de modo integral, pois os indivíduos com tendência suicida acabam tendo o primeiro contato com um profissional da educação para falar sobre as tentativas de suicídio ou demonstrar tais práticas e, assim, será possível contatar 
profissionais da área social e da saúde para lidar com essa situação de risco, buscando a melhor maneira de proporcionar um tratamento adequado para essas pessoas.

A pesquisa tinha o objetivo de entrevistar 145 acadêmicos, porém o número de participantes entrevistados foi menor que o projetado em decorrência do estado de quarentena decretada no município de Campo Grande, Mato Grosso do Sul, como forma de evitar a propagação do COVID-19, dificultando a continuidade das entrevistas, não alcançando o número desejado de acadêmicos, como previsto inicialmente. Foram, então, entrevistados cento e trinta e seis acadêmicos dos cursos de Medicina (46), Psicologia (28), Matemática (31), Pedagogia (13) e Serviço social (18) da Universidade Anhanguera-Uniderp, campus matriz.

As questões de número 1 e 2 seguiam os critérios de inclusão do participante para a pesquisa. As questões de número 3 a 16 foram elaboradas a partir de dois materiais: o primeiro material utilizado foi um documento produzido, em 2014, pela Sociedade Brasileira de Psiquiatria (ABP) em conjunto com o Conselho Federal de Medicina (CFM), com o seguinte título "Suicídio: Informar Para Prevenir". O segundo material utilizado envolve os cartazes sobre suicídio, produzidos em 2018 para divulgação da conscientização e da prevenção no mês de setembro, realizando referências à campanha setembro amarelo ${ }^{1}$. Os dois materiais utilizados possuem uma fundamentação científica, oferecem uma linguagem acessível à sociedade, de modo geral, contribuindo para a formulação das questões, que compuseram o questionário, tornando as perguntas acessíveis e de fácil compreensão em relação ao tema que foi abordado com os participantes da pesquisa.

Conforme exposto, a intenção era abranger um número maior de acadêmicos. Número este obtido por meio de cálculos de amostragem para se obter uma amostra representativa com 95\% de confiança. No entanto, a COVID-19 trouxe dificuldades para a continuidade e se adotou, então, a amostra por conveniência.

\section{Resultados e Discussão}

No Brasil, em 2015, foi criada a campanha de conscientização sobre prevenção ao suicídio, denominada "Setembro Amarelo", com envolvimento de escolas, de Universidades, entidades públicas e privadas de Norte ao Sul do Brasil (CVV, 2019). Buscando-se saber a cobertura que este tipo de ação tem dentro do público jovem, realizou-se um questionamento, no qual entre os entrevistados, 98,52\% responderam se tiveram ou não contato com campanhas sobre o tratamento que se deve dispensar a uma pessoa com tendência suicida. Como verificado no Quadro 1, um pouco mais da metade dos acadêmicos negou ter tido esse contato, demonstrando que campanhas abordando esse conteúdo ainda não alcançou todas as esferas.
Quadro 1 - Conhece alguma campanha sobre o tratamento que se deve dispensar a uma pessoa com tendência suicida

\begin{tabular}{|c|c|c|c|c|c|c|}
\hline & MED & MT & PD & PS & SS & Total \\
\hline \multirow{2}{*}{ Não } & 25 & 19 & 8 & 8 & 10 & 70 \\
& $(54,3 \%)$ & $(61,3 \%)$ & $(61,5 \%)$ & $(29,6 \%)$ & $(58,8 \%)$ & $(51,5 \%)$ \\
\hline \multirow{2}{*}{ Sim } & 21 & 12 & 5 & 19 & 7 & 64 \\
& $(45,7 \%)$ & $(38,7 \%)$ & $(38,5 \%)$ & $(70,4 \%)$ & $(42,2 \%)$ & $(47,1 \%)$ \\
\hline Total & 46 & 31 & 13 & 27 & 17 & 134 \\
\hline
\end{tabular}

Entre todos acadêmicos, a maior taxa de contato com as campanhas é representada pelos de Psicologia (PS), seguido em segundo e terceiro lugar pelos de Medicina (MED) e Serviço Social (SS), respectivamente. Apesar disso, nos dois últimos cursos, um pouco mais da metade dos estudantes não teve acesso a essas campanhas. Os cursos de Matemática (MT) e Pedagogia (PD) tiveram padrão semelhante com desconhecimento maior que $60 \%$ acerca dessas campanhas. O baixo grau de contato com as campanhas do Setembro Amarelo pode ser explicado pelo seu incipiente início, o que impossibilita julgá-la como efetiva ou não efetiva.

Essas campanhas possuem, entre outras funções, a finalidade de combater a mitos sobre o suicídio. Entre os principais mitos se destaca a afirmativa de que pessoas que pronunciam ou dão sinais sobre suas ideias de morte querem apenas chamar a atenção, o que é falso, haja vista o fato de que em dias ou semanas pregressas, muitos suicidas expressaram o desejo de se matar a outras pessoas, como profissionais de saúde (CFM; ABP, 2014). No que tange a isso, questionouse aos entrevistados sobre o pronunciamento do desejo de se suicidar e a relação com o fato mais provável.

De acordo com a Quadro 2, entre o total de entrevistados que responderam a esse item, quase $90 \%$ deles acreditam que é provável que essa pessoa pratique o suicídio e o restante se divide, igualmente, entre os que acreditam que isso seja apenas uma chantagem ou que a pessoa nunca chegue a executar o plano suicida. Com relação à opinião dos acadêmicos sobre essa problemática, observou-se que há similaridade entre os entrevistados dos cursos de Medicina e Psicologia, pois apenas um indivíduo de cada grupo acredita que a pessoa nunca execute o plano e todos os outros creem que o mais provável é a execução do suicídio.

No curso de Serviço Social, por sua vez, os acadêmicos dividem opiniões entre a possibilidade de execução ou de chantagem, porém em sua grande maioria apostam na primeira opção. Quanto aos cursos de Pedagogia e Matemática, houve distribuição entre as três opções propostas, porém no primeiro grupo menos de $8 \%$ supõe que os indivíduos, que ameaçam, nunca se suicidarão, enquanto no segundo mais de $16 \%$ creem da mesma maneira. Cabe destacar que somente no curso de Psicologia a maioria dos acadêmicos teve acesso a essa informação, possivelmente, por influência dos seus professores. Além disso, no curso de Serviço Social em que se 
espera uma postura orientada a promover o bem-estar coletivo, foi detectada precária abordagem da temática das campanhas do Setembro Amarelo, o que sugere ser um reflexo da própria estruturação e condução do processo de formação acadêmica.

Quadro 2 - Quando uma pessoa diz que quer se suicidar o mais provável é que ela

\begin{tabular}{|c|c|c|c|c|c|c|}
\hline & MED & MT & PD & PS & SS & Total \\
\hline $\begin{array}{c}\text { Chegue a } \\
\text { praticar o } \\
\text { suicídio }\end{array}$ & $\begin{array}{c}45 \\
(97,8 \%)\end{array}$ & $\begin{array}{c}21 \\
(70,0 \%)\end{array}$ & $\begin{array}{c}10 \\
(76,9 \%)\end{array}$ & $\begin{array}{c}27 \\
(96,4 \%)\end{array}$ & $\begin{array}{c}16 \\
(88,9 \%)\end{array}$ & $\begin{array}{c}119 \\
(87,5 \%)\end{array}$ \\
\hline $\begin{array}{c}\text { Esteja } \\
\text { apenas } \\
\text { querendo } \\
\text { chantagear }\end{array}$ & 0 & 4 & 2 & 0 & 2 & 8 \\
$(0,0 \%)$ & $(13,3 \%)$ & $(15,4 \%)$ & $(0,0 \%)$ & $(11,1 \%)$ & $(5,9) \%$ \\
\hline $\begin{array}{c}\text { Nunca } \\
\text { chegue a } \\
\text { executar o } \\
\text { plano }\end{array}$ & 1 & $\begin{array}{c}5 \\
(2,2 \%)\end{array}$ & $\begin{array}{c}1 \\
(16,7 \%)\end{array}$ & $\begin{array}{c}1 \\
(7,7 \%)\end{array}$ & $\begin{array}{c}0 \\
(3,6 \%)\end{array}$ & $\begin{array}{c}8 \\
(0,0 \%)\end{array}$ \\
\hline Total & 46 & 30 & 13 & 28 & 18 & 135 \\
\hline
\end{tabular}

Fonte: Dados da Pesquisa.

Além disso, outra afirmativa que se enquadra nos mitos acerca do suicídio é: pessoas que em um instante quer se matar e em outro se encontra tranquila é porque desistiu do ato de se suicidar. De acordo com o Conselho Federal de Medicina e Associação Brasileira de Psiquiatria (2014), isto é um pensamento falso, pois transparecer alívio e calma não representa o desaparecimento do sofrimento nem tampouco a ausência de quaisquer comportamentos suicidas. Essa relação foi abordada no questionário, sendo respondida por todos os entrevistados e representado no Quadro 3, que aponta mais de $70 \%$ discordância desse mito; 7,35\% deles afirmam que a calma representa uma resignação da ideia suicida e, 16,17\%, não souberam responder.

Observou-se uma equivalência entre os entrevistados do curso de Medicina, Psicologia e Serviço Social, visto que apenas um participante de cada curso está enquadrado nos $7,35 \%$. Matemática foi o curso que obteve maior número de indivíduos participantes, que concordam com a visão da tranquilidade representar desistência, correspondendo um total de $50 \%$ desses acadêmicos, de sua angústia ao se encontrar uma saída ao seu sofrimento. Nesse ponto fica evidente a necessidade de maior protagonismo dos professores, no que diz respeito à orientação dos licenciandos, tendo em vista que trabalharão diretamente com jovens e, muitos deles, em comunidades carentes. O pressuposto é que a sala de aula não provocou a necessidade de busca por informações sobre o tema.

Quadro 3 - Se apresenta tranquilidade (se mostra calma) é porque desistiu da ideia de se suicidar

\begin{tabular}{|l|c|c|c|c|c|c|}
\hline & MED & MT & PD & PS & SS & Total \\
\hline $\begin{array}{l}\text { Concordo } \\
\text { parcialmente }\end{array}$ & 1 & 5 & 2 & 1 & 0 & 9 \\
$(2,2 \%)$ & $(16,1 \%)$ & $(15,4 \%)$ & $(3,6 \%)$ & $(0,0 \%)$ & $(6,6 \%)$ \\
\hline $\begin{array}{l}\text { Concordo } \\
\text { totalmente }\end{array}$ & 0 & 0 & 0 & 0 & 1 & 1 \\
\hline $\begin{array}{l}\text { Discordo } \\
\text { parcialmente }\end{array}$ & $(19,0 \%)$ & $(0,0 \%)$ & $(0,0 \%)$ & $(0,0 \%)$ & $(5,6 \%)$ & $(0,7 \%)$ \\
\hline
\end{tabular}

\begin{tabular}{|l|c|c|c|c|c|c|}
\hline & MED & MT & PD & PS & SS & Total \\
\hline Discordo & 34 & 9 & 5 & 18 & 8 & 74 \\
totalmente & $(73,9 \%)$ & $(29,0 \%)$ & $(38,4 \%)$ & $(64,3 \%)$ & $(44,4 \%)$ & $(54,4 \%)$ \\
\hline $\begin{array}{l}\text { Tenho } \\
\text { dúvida }\end{array}$ & 2 & 8 & 5 & 4 & 3 & 22 \\
\hline Total & $4,3 \%)$ & $(25,8 \%)$ & $(38,4 \%)$ & $(14,3 \%)$ & $(16,7 \%)$ & $(16,2 \%)$ \\
\hline
\end{tabular}

Fonte: Dados da pesquisa.

Ademais, foi realizada outra abordagem acerca da tranquilidade da pessoa que se encontrava em risco de suicídio, em que se colocou em questão a relação existente entre a tranquilidade e a decisão de adotar um comportamento suicida, como representado no Quadro 4. Um dado muito relevante é que a maioria acredita que a calmaria não está relacionada à decisão e preparação para o ato de atentar contra sua própria vida, sendo que o curso de maior representatividade foi Medicina, com cerca de $42 \%$ e o de menor foi Pedagogia com $3,5 \%$.

Quadro 4 - Se apresenta tranquilidade (se mostra calma) é porque já definiu que vai suicidar e está se preparando para a execução do ato

\begin{tabular}{|c|c|c|c|c|c|c|}
\hline & MED & MT & PD & PS & SS & \\
\hline $\begin{array}{l}\text { Concordo } \\
\text { parcialmente }\end{array}$ & $\begin{array}{c}11 \\
(23,9 \%)\end{array}$ & $\begin{array}{c}6 \\
(19,4 \%)\end{array}$ & $\begin{array}{c}6 \\
(46,2 \%)\end{array}$ & $\begin{array}{c}8 \\
(28,6 \%)\end{array}$ & $\begin{array}{c}3 \\
(16,7 \%)\end{array}$ & $\begin{array}{c}34 \\
(25,0 \%)\end{array}$ \\
\hline & \begin{tabular}{|c|}
2 \\
$(4,3 \%)$ \\
\end{tabular} & $\begin{array}{c}2 \\
(6,5 \%) \\
\end{array}$ & $\begin{array}{c}1 \\
(7,7 \%) \\
\end{array}$ & \begin{tabular}{|c|}
2 \\
$(7,1 \%)$ \\
\end{tabular} & $\begin{array}{c}1 \\
(5,6 \%) \\
\end{array}$ & \begin{tabular}{|c|}
8 \\
$(5,9 \%)$ \\
\end{tabular} \\
\hline $\begin{array}{l}\text { Discc } \\
\text { parci }\end{array}$ & $\begin{array}{c}14 \\
(30,4 \%)\end{array}$ & $\begin{array}{c}9 \\
(29,0 \%)\end{array}$ & $\begin{array}{c}1 \\
(7,7 \%)\end{array}$ & $\begin{array}{c}8 \\
(28,6 \%)\end{array}$ & $\begin{array}{c}7 \\
(38,9 \%)\end{array}$ & $\begin{array}{c}39 \\
(28,7 \%)\end{array}$ \\
\hline $\begin{array}{l}\text { Disco } \\
\text { totalm }\end{array}$ & $\begin{array}{c}10 \\
(21,7 \%)\end{array}$ & $\begin{array}{c}1 \\
(3,2 \%)\end{array}$ & $\begin{array}{c}1 \\
(7,7 \%)\end{array}$ & $\begin{array}{c}4 \\
(14,3 \%)\end{array}$ & $\begin{array}{c}2 \\
(11,1 \%)\end{array}$ & $\begin{array}{c}18 \\
(13,2 \%)\end{array}$ \\
\hline $\begin{array}{l}\text { Tenho } \\
\text { dúvida }\end{array}$ & $\begin{array}{c}9 \\
(19,6 \%)\end{array}$ & $\begin{array}{c}13 \\
(41,9 \%)\end{array}$ & $\begin{array}{c}4 \\
(30,8 \%)\end{array}$ & $\begin{array}{c}6 \\
(21,4 \%)\end{array}$ & $\begin{array}{c}5 \\
(27,8 \%)\end{array}$ & $\begin{array}{c}37 \\
(27,2 \%)\end{array}$ \\
\hline Total & 46 & 31 & 13 & 28 & 18 & 136 \\
\hline
\end{tabular}

Fonte: Dados da pesquisa.

Entretanto, Medicina também foi o curso que ficou em primeiro lugar entre os concordantes. Dessa forma, percebe-se uma discrepância na qualidade da informação recebida por esses acadêmicos ou, até mesmo, a não chegada para alguns, já que contraria o material explanado pelo Conselho Federal de Medicina e Associação Brasileira de Psiquiatria (2014), que aponta a tranquilidade como comportamento puramente resultante do planejamento do suicídio, ferramenta esta utilizada como alívio.

Em contrapartida, associou-se à decisão e o planejamento do suicídio com agitação ou agressividade. Entre o total de entrevistados, 99,26\% responderam ao questionamento. Como observado no Quadro 5, embora se tenha observado uma divisão de opiniões, há uma semelhança entre os cursos de Medicina, Matemática e Psicologia, entre os quais a maioria não acredita que exista essa correlação; destes se destaca o primeiro, que corresponde a aproximadamente $46 \%$ do total de discordantes. Entretanto, no curso de Serviço Social houve um predomínio relativamente pequeno de acadêmicos que concordam com a tese que a inquietação é decorrente da escolha de se suicidar; cerca de $38 \%$. 
Quadro 5 - Se apresenta agitada ou agressiva é porque já definiu que vai suicidar e está se preparando para a execução do ato

\begin{tabular}{|l|c|c|c|c|c|c|}
\hline & MED & MT & PD & PS & SS & Total \\
\hline $\begin{array}{l}\text { Concordo } \\
\text { parcialmente }\end{array}$ & 6 & 8 & 3 & 7 & 5 & 29 \\
$(13,0 \%)$ & $(26,7 \%)$ & $(23,1 \%)$ & $(25,0 \%)$ & $(27,8 \%)$ & $(21,5 \%)$ \\
\hline $\begin{array}{l}\text { Concordo } \\
\text { totalmente }\end{array}$ & 0 & 0 & 1 & 1 & 2 & 4 \\
$(0,0 \%)$ & $(0,00 \%)$ & $(7,7 \%)$ & $(3,6 \%)$ & $(11,1 \%)$ & $(3,0 \%)$ \\
\hline $\begin{array}{l}\text { Discordo } \\
\text { parcialmente }\end{array}$ & $\begin{array}{c}21 \\
(45,7 \%)\end{array}$ & $\begin{array}{c}(33,3 \%) \\
(0,0 \%)\end{array}$ & $\begin{array}{c}(35,7 \%) \\
(22,2 \%)\end{array}$ & $\begin{array}{c}43,3 \%) \\
(33,3 \%)\end{array}$ \\
\hline $\begin{array}{l}\text { Discordo } \\
\text { totalmente }\end{array}$ & $\begin{array}{c}(28,3 \%) \\
(20,0 \%)\end{array}$ & $\begin{array}{c}(30,8 \%) \\
(14,3 \%)\end{array}$ & $\begin{array}{c}1 \\
(5,6 \%)\end{array}$ & $\begin{array}{c}28,7 \%) \\
(20,7 \%)\end{array}$ \\
\hline $\begin{array}{l}\text { Tenho } \\
\text { dúvida }\end{array}$ & 6 & 6 & 5 & 6 & 6 & 29 \\
\hline Total & $(13,0 \%)$ & $(20,0 \%)$ & $(38,5 \%)$. & $(21,4 \%)$ & $(33,3 \%)$ & $(21,5 \%)$ \\
\hline
\end{tabular}

Ainda, foi questionado se atitudes agressivas representam uma indecisão sobre qual atitude tomar. Sobre isso, constatouse que os mesmos ficaram bem divididos em suas opiniões, visto que cerca de $41 \%$ não considera verídica essa relação e $40 \%$ afirmaram concordar. Do primeiro, evidencia-se Medicina, Matemática e Serviço Social; já os últimos se destacam Pedagogia e Psicologia (Quadro 6).

Quadro 6 - Se apresenta agitada ou agressiva é porque está indecisa sobre o que deve fazer

\begin{tabular}{|l|c|c|c|c|c|c|}
\hline & MED & MT & PD & PS & SS & Total \\
\hline $\begin{array}{l}\text { Concordo } \\
\text { parcialmente }\end{array}$ & $\begin{array}{c}12 \\
(26,1 \%)\end{array}$ & $\begin{array}{c}7 \\
(23,3 \%)\end{array}$ & $\begin{array}{c}6 \\
(46,2 \%)\end{array}$ & $\begin{array}{c}12 \\
(42,9 \%)\end{array}$ & $\begin{array}{c}5 \\
(27,8 \%)\end{array}$ & $\begin{array}{c}42 \\
(31,1 \%)\end{array}$ \\
\hline $\begin{array}{l}\text { Concordo } \\
\text { totalmente }\end{array}$ & $\begin{array}{c}(13,0 \%) \\
(11,0 \%)\end{array}$ & $\begin{array}{c}0 \\
(0,0 \%)\end{array}$ & $\begin{array}{c}1 \\
(3,6 \%)\end{array}$ & $\begin{array}{c}2 \\
(11,1 \%)\end{array}$ & $\begin{array}{c}12 \\
(8.9 \%)\end{array}$ \\
\hline $\begin{array}{l}\text { Discordo } \\
\text { parcialmente }\end{array}$ & $\begin{array}{c}(28,3 \%) \\
(36,7 \%)\end{array}$ & $\begin{array}{c}11 \\
(0,0 \%)\end{array}$ & $\begin{array}{c}6 \\
(21,4 \%)\end{array}$ & $\begin{array}{c}4 \\
(22,2 \%)\end{array}$ & $\begin{array}{c}34 \\
(25,2 \%)\end{array}$ \\
\hline $\begin{array}{l}\text { Discordo } \\
\text { totalmente }\end{array}$ & 7 & 2 & 3 & 4 & 6 & 22 \\
\hline $\begin{array}{l}\text { Tenho } \\
\text { dúvida }\end{array}$ & $(15,2 \%)$ & $(6,7 \%)$ & $(23,1 \%)$ & $(14,3 \%)$ & $(33,3 \%)$ & $(16,3 \%)$ \\
\hline Total & $(17,4 \%)$ & 7 & 4 & 5 & 1 & 25 \\
& 46 & 30 & 13 & 28 & 18 & 135 \\
\hline
\end{tabular}

Fonte: Dados da pesquisa.

Tendo-se em vista que a ideação suicida é um fenômeno complexo, o indivíduo em risco de suicídio pode se apresentar, tanto com tranquilidade pela decisão de se matar ou agitação dentro do espectro de distúrbios psiquiátricos, em que uma agitação psicomotora é resultante de um excesso de atividade motora em conjunto com alguma experiência estressante (DEL-BEN et al., 2017). Alguns transtornos mentais, como esquizofrenia e transtorno bipolar, ou de personalidade, intoxicação medicamentosa ou por substâncias psicoativas, abstinência alcoólica e infecções também podem ser responsáveis pela agitação (DEL-BEN et al., 2017).

Dessa maneira, os resultados presentes nos Quadros 5 e 6 expõem a realidade de carência de tecnicidade no conhecimento dos estudantes dentro da Universidade, no que tange à temática do suicídio. Isso é um fator desfavorável na formação no futuro profissional desses estudantes, haja vista que uma conduta inadequada no trato com indivíduo em risco pode possibilitar que o desejo e o planejamento de morte seja efetivado (CFM; ABP, 2014).

Ademais, foi questionado quanto à necessidade de a pessoa, em tendência suicida, ter acesso a atendimento especializado. Os acadêmicos do curso de Serviço Social, de modo unânime, concordaram totalmente em ser necessário a abordagem pelo especialista. Enquanto, os de Pedagogia foram os únicos que ficaram em dúvida acerca disso (não concordaram nem discordaram), apesar de a maior parte considerar o atendimento especializado imprescindível.

Por outro lado, a grande maioria dos participantes dos cursos de Medicina, de Matemática e de Psicologia concordar totalmente com a necessidade desses pacientes receberem assistência especializada. Em geral, observou-se que bom nível de compreensão dos participantes sobre tal tópico, uma vez que o comportamento suicida é uma emergência médica e, portanto, representa um cenário de intenso sofrimento ou risco iminente de morte, que exige tratamento médico imediato (DAUDT et. al., 2018; BRASIL, 2014) (Quadro 7).

Quadro 7 - Uma pessoa com tendência suicida precisa de atendimento especializado

\begin{tabular}{|l|c|c|c|c|c|c|}
\hline & MED & MT & PD & PS & SS & Total \\
\hline $\begin{array}{l}\text { Concordo } \\
\text { parcialmente }\end{array}$ & 2 & 4 & 0 & 1 & 0 & 7 \\
$(4,3 \%)$ & $(13,3 \%)$ & $(0,0 \%)$ & $(3,6 \%)$ & $(0,0 \%)$ & $(5,2 \%)$ \\
\hline $\begin{array}{l}\text { Concordo } \\
\text { totalmente }\end{array}$ & 44 & 26 & 11 & 27 & 18 & 126 \\
$(95,7 \%)$ & $(86,7 \%)$ & $(84,6 \%)$ & $(96,4 \%)$ & $(100,0 \%)$ & $(93,3 \%)$ \\
\hline $\begin{array}{l}\text { Tenho } \\
\text { dúvida }\end{array}$ & 0 & 0 & 2 & 0 & 0 & 2 \\
\hline Total & $(0,0 \%)$ & $(0,0 \%)$ & $(15,4 \%)$ & $(0,0 \%)$ & $(0,0 \%)$ & $(1,5 \%)$ \\
\hline
\end{tabular}

Fonte: Dados da pesquisa.

Na abordagem inicial, o conhecimento acerca dos fatores de riscos e protetores é fundamental para a estratificação e direcionamento em um fluxo de atendimento. Na unidade de urgência e emergência, objetiva-se reduzir o risco imediato; controlar fatores predisponentes e promover seguimento. Quanto à estratificação em baixo risco, os pacientes devem receber uma escuta acolhedora, além de facilitar vinculação aos suportes ambientais e realizar tratamento de possível transtorno psiquiátrico.

Em casos refratários se recomenda encaminhamento ao especialista. Nos casos de risco médio, por sua vez, o atendimento especializado deve acontecer o mais rápido possível e faz-se necessária a remoção de objetos como armas, facas e cordas. Em situações de alto risco, nunca se deve deixar a pessoa sozinha, referenciar para o serviço de psiquiatria para avaliação e, se necessário, realiza-se a internação. Caso não seja possível, considere o caso como emergência e entre em contato com um profissional da saúde mental ou do serviço de emergência mais próximo (CFM; ABP, 2014).

A pesquisa não demonstra que os acadêmicos têm conhecimento profundo do anteriormente exposto, porém aponta que de modo independente eles possuem certo grau de ciência sobre o tema, que contribui para a promoção em saúde. No entanto, caso haja um aprofundamento dos assuntos 
abordados, a assistência ao indivíduo em risco suicida poderá ser de melhor qualidade.

Durante esse processo de estratificação do risco é de suma importância que o profissional inclua no atendimento alguns elementos básicos como o ouvir, a tolerância a ambivalência do paciente, que oscila entre momentos com ou sem pensamentos suicidas e o ponto de apoio que permita o atendimento continuado posteriormente (BERLOTE; MELlO-SANTOS; BOTEGA, 2010). Perante tais fatos se compreende a necessidade explícita da capacitação profissional como ferramenta de combate ao suicídio. Isso se desenvolve de modo mais efetivo, a partir da elaboração de assistência multidisciplinar (WHO, 2000).

Nesse contexto se inserem ainda trabalhos prévios como o Estudo Multicêntrico de Intervenção no Comportamento Suicida (WHO, 2002), em que os pacientes atendidos nos serviços de urgência/emergência, após tentativa de suicídio, receberem dois seguimentos distintos: o tratamento usual com encaminhamento após a alta hospitalar e intervenção psicossocial com entrevista motivacional e acompanhamento regular via telefônica. Após 18 meses, identificou-se que o primeiro grupo apresentou 18 óbitos por suicídio, enquanto o segundo, apenas dois (FLEISCHMANN et al., 2008).

Assim, é evidente o quão importante é o ouvir na atenção dispensada ao indivíduo em tendência suicida. Além disso, na "Carta aos pais, responsáveis e educadores" é reforçado que o debate sobre o suicídio deve ocorrer tanto no âmbito escolar quanto residencial (ABP; CFM; APAL, 2019). Em decorrência dessa discussão, foi questionado se ignorar a fala de uma pessoa em tendência suicida se enquadra como conduta ideal para evitar a estimulação do ato. Como observado no Quadro 8, a maioria dos participantes discorda, com predomínio dos acadêmicos de Medicina, seguidos pelo de Psicologia. Apenas dois acadêmicos concordaram que se deve ignorar a fala, os quais coincidentemente não haviam tido acesso a quaisquer materiais informativos acerca do tratamento dispensado para a pessoa em risco de suicídio.

Quadro 8 - Uma pessoa com tendência suicida deve ter a sua fala ignorada pelo profissional ou familiar na tentativa de não estimular o ato

\begin{tabular}{|l|c|c|c|c|c|c|}
\hline & MED & MT & PD & PS & SS & Total \\
\hline $\begin{array}{l}\text { Concordo } \\
\text { totalmente }\end{array}$ & $\begin{array}{c}2 \\
(4,4 \%)\end{array}$ & $\begin{array}{c}0 \\
(0,0 \%)\end{array}$ & $\begin{array}{c}0 \\
(0,0 \%)\end{array}$ & $\begin{array}{c}0 \\
(0,0 \%)\end{array}$ & $\begin{array}{c}0 \\
(0,0 \%)\end{array}$ & $\begin{array}{c}2 \\
(1,5 \%)\end{array}$ \\
\hline $\begin{array}{l}\text { Discordo } \\
\text { parcialmente }\end{array}$ & $\begin{array}{c}(2,3 \%) \\
(6,7 \%)\end{array}$ & $\begin{array}{c}0 \\
(0,0 \%)\end{array}$ & $\begin{array}{c}1 \\
(3,6 \%)\end{array}$ & $\begin{array}{c}0 \\
(0,0 \%)\end{array}$ & $\begin{array}{c}4 \\
(3,0 \%)\end{array}$ \\
\hline $\begin{array}{l}\text { Discordo } \\
\text { totalmente }\end{array}$ & $\begin{array}{c}39 \\
(92,9 \%)\end{array}$ & $\begin{array}{c}24 \\
(80,0 \%)\end{array}$ & $\begin{array}{c}(69,2 \%) \\
(92,9 \%)\end{array}$ & $\begin{array}{c}17 \\
(94,4 \%)\end{array}$ & $\begin{array}{c}115 \\
(85.8 \%)\end{array}$ \\
\hline $\begin{array}{l}\text { Tenho } \\
\text { dúvida }\end{array}$ & $\begin{array}{c}3 \\
(6,7 \%)\end{array}$ & $\begin{array}{c}4 \\
(13,3 \%)\end{array}$ & $\begin{array}{c}4 \\
(30,8 \%)\end{array}$ & $\begin{array}{c}1 \\
(3,6 \%)\end{array}$ & $\begin{array}{c}1 \\
(5,6 \%)\end{array}$ & $\begin{array}{c}13 \\
(9,7 \%)\end{array}$ \\
\hline Total & 45 & 30 & 13 & 28 & 18 & 134 \\
\hline
\end{tabular}

Fonte: Dados da pesquisa.

Outro aspecto abordado no questionário foi compressão do perfil de atendimento a um indivíduo em tendência suicida realizado pelos profissionais. Isso foi questionado por meio de três itens, em que se indagou a concordância ou não com estes perfis de pessoas: "alguém que não quer se esforçar", "alguém que está sofrendo muito" e "alguém que quer chantagear". O Quadro 9 mostra as respostas obtidas em relação ao primeiro item. Os únicos cursos em que nenhum dos participantes concorda em ser falta de esforço foram os de Medicina e Psicologia. Apesar disso, entre os todos os participantes, que responderam a esse item, mais de $76 \%$ discordaram totalmente. Por outro lado, quanto à compreensão do estado de sofrimento, os dados que se encontram no Quadro 10 informam que a maioria está de acordo com a afirmação de que uma pessoa com pensamento suicida está sofrendo muito, o que corresponde a mais de $68 \%$. Entre os discordantes, os cursos que se destacam são Medicina e Serviço Social.

Quadro 9 - Uma pessoa com tendência suicida deve ser atendida como "alguém que não quer se esforçar"

\begin{tabular}{|c|c|c|c|c|c|c|}
\hline & MED & MT & PD & PS & SS & Total \\
\hline $\begin{array}{l}\text { Concordo } \\
\text { parcialmente }\end{array}$ & $\begin{array}{c}0 \\
(0,0 \%)\end{array}$ & $\begin{array}{c}1 \\
(3,3 \%)\end{array}$ & $\begin{array}{c}1 \\
(7,7 \%)\end{array}$ & $\begin{array}{c}0 \\
(0,0 \%)\end{array}$ & $\begin{array}{c}1 \\
(5,6 \%)\end{array}$ & $\begin{array}{c}3 \\
(2,3 \%) \\
\end{array}$ \\
\hline $\begin{array}{l}\text { Concordo } \\
\text { totalmente }\end{array}$ & $\begin{array}{c}0 \\
(0,0 \%)\end{array}$ & $\begin{array}{c}2 \\
(6,7 \%)\end{array}$ & $\begin{array}{c}1 \\
(7,5 \%)\end{array}$ & $\begin{array}{c}0 \\
(0,0 \%)\end{array}$ & $\begin{array}{c}1 \\
(5,6 \%)\end{array}$ & $\begin{array}{c}4 \\
(3,0 \%)\end{array}$ \\
\hline $\begin{array}{l}\text { Discordo } \\
\text { parcialmente }\end{array}$ & $\begin{array}{c}1 \\
(2,3 \%)\end{array}$ & $\begin{array}{c}10 \\
(33,3 \%) \\
\end{array}$ & $\begin{array}{c}2 \\
(15,4 \%)\end{array}$ & $\begin{array}{c}3 \\
(10,7 \%)\end{array}$ & $\begin{array}{c}1( \\
5,6 \%) \\
\end{array}$ & $\begin{array}{c}17 \\
(12,8 \%)\end{array}$ \\
\hline $\begin{array}{l}\text { Discordo } \\
\text { totalmente }\end{array}$ & $\begin{array}{c}42 \\
(95,5 \%)\end{array}$ & $\begin{array}{c}15 \\
(50,0 \%)\end{array}$ & $\begin{array}{c}7 \\
(53,8 \%) \\
\end{array}$ & $\begin{array}{c}24 \\
(85,7 \%)\end{array}$ & $\begin{array}{c}14 \\
(77,8 \%)\end{array}$ & $\begin{array}{c}102 \\
(76,7 \%)\end{array}$ \\
\hline $\begin{array}{l}\text { Tenho } \\
\text { dúvida }\end{array}$ & $\begin{array}{c}1 \\
(2,3 \%)\end{array}$ & $\begin{array}{c}2 \\
(6,7 \%)\end{array}$ & $\begin{array}{c}2 \\
(15,4 \%)\end{array}$ & $\begin{array}{c}1 \\
(3,6 \%)\end{array}$ & $\begin{array}{c}1 \\
(5,6 \%)\end{array}$ & $\begin{array}{c}7 \\
(5,5 \%)\end{array}$ \\
\hline Total & 44 & 30 & 13 & 28 & 18 & 133 \\
\hline
\end{tabular}

Fonte: Dados da pesquisa.

Quadro 10 - Uma pessoa com tendência suicida deve ser atendida como "alguém que está sofrendo muito"

\begin{tabular}{|l|c|c|c|c|c|c|}
\hline & MED & MT & PD & PS & SS & Total \\
\hline $\begin{array}{l}\text { Concordo } \\
\text { parcialmente }\end{array}$ & $\begin{array}{c}8 \\
(17,8 \%)\end{array}$ & $\begin{array}{c}15 \\
(50,0 \%)\end{array}$ & $\begin{array}{c}0 \\
(0,0 \%)\end{array}$ & $\begin{array}{c}8 \\
(28,6 \%)\end{array}$ & $\begin{array}{c}3 \\
(16,7 \%)\end{array}$ & $\begin{array}{c}34 \\
(25,4 \%)\end{array}$ \\
\hline $\begin{array}{l}\text { Concordo } \\
\text { totalmente }\end{array}$ & 18 & 8 & 8 & 15 & 9 & 58 \\
$(40,0 \%)$ & $(26,7 \%)$ & $(61,5 \%)$ & $(53,6 \%)$ & $(50,0 \%)$ & $(43,3 \%)$ \\
\hline $\begin{array}{l}\text { Discordo } \\
\text { parcialmente }\end{array}$ & 12 & 4 & 3 & 3 & 2 & 24 \\
Discordo & 3 & 1 & 0 & 0 & 4 & 8 \\
totalmente & $(6,7 \%)$ & $(3,3 \%)$ & $(0,0 \%)$ & $(0,0 \%)$ & $(22,2 \%)$ & $(6,0 \%)$ \\
\hline $\begin{array}{l}\text { Tenho } \\
\text { dúvida }\end{array}$ & 4 & 2 & 2 & 2 & 0 & 10 \\
\hline Total & $(8,95 \%)$ & $(6,7 \%)$ & $(15,4 \%)$ & $(7,1 \%)$ & $(0,0 \%)$ & $(7,5 \%)$ \\
\hline
\end{tabular}

Fonte: Dados da pesquisa.

Em relação à percepção do indivíduo, em tendência suicida, como um chantagista, registrada no Quadro 11, cerca de $88 \%$ dos que responderam discordaram, entre os quais se destacam os acadêmicos do curso de Medicina, que discordam disso em uma taxa maior que 97\%. Diferentemente desse perfil, os estudantes de Matemática representaram 70\% dos que acreditam ser chantagem. 
Tabela 11 - Uma pessoa com tendência suicida deve ser atendida como "alguém que quer chantagear"

\begin{tabular}{|l|c|c|c|c|c|c|}
\hline & MED & MT & PD & PS & SS & Total \\
\hline $\begin{array}{l}\text { Concordo } \\
\text { parcialmente }\end{array}$ & 0 & 6 & 1 & 0 & 2 & 9 \\
$(0,0 \%)$ & $(20,0 \%)$ & $(7,7 \%)$ & $(0,0 \%)$ & $(11,1 \%)$ & $(6,7 \%)$ \\
\hline $\begin{array}{l}\text { Concordo } \\
\text { totalmente }\end{array}$ & 0 & 1 & 0 & 0 & 0 & 1 \\
$(0.0 \%)$ & $(3,3 \%)$ & $(0,0 \%)$ & $(0,0 \%)$ & $(0,0 \%)$ & $(0,7 \%)$ \\
\hline $\begin{array}{l}\text { Discordo } \\
\text { parcialmente }\end{array}$ & $\begin{array}{c}(8,9 \%) \\
(16,7 \%)\end{array}$ & $\begin{array}{c}(23,1 \%) \\
(7,1 \%)\end{array}$ & $\begin{array}{c}(11,1 \%) \\
(11,9 \%)\end{array}$ \\
\hline $\begin{array}{l}\text { Discordo } \\
\text { totalmente }\end{array}$ & $\begin{array}{c}(80,9 \%) \\
(56,7 \%)\end{array}$ & $\begin{array}{c}(53,8 \%) \\
(85.7 \%)\end{array}$ & $\begin{array}{c}(77,8 \%) \\
(76,1 \%)\end{array}$ \\
\hline $\begin{array}{l}\text { Tenho } \\
\text { dúvida }\end{array}$ & 1 & $(2,2 \%)$ & $1(3,3 \%)$ & $\begin{array}{c}(15,4 \%) \\
(7,1 \%)\end{array}$ & $\begin{array}{c}2 \\
(0,0 \%)\end{array}$ & $\begin{array}{c}6 \\
(4,5 \%)\end{array}$ \\
\hline \multicolumn{1}{|c|}{ Total } & 45 & 30 & 13 & 28 & 18 & 134 \\
\hline
\end{tabular}

Fonte: Dados da pesquisa.

Diante dessa realidade, Cassorla (1998) contribui ao afirmar que o suicida não quer morrer, mas pelo contrário anseia fugir de um sofrimento insuportável. Esse autor acrescenta ainda que o suicídio se expressa como recurso de solução para todas as dificuldades enfrentadas pelo indivíduo (CASSORLA, 2005). Diante desse contexto, compreendese que a expressão do desejo de suicídio jamais deva ser interpretada como chantagem emocional, nem banalizado como falta de esforço para viver, mas pelo contrário, é necessário entender o pedido de ajuda, oferecer apoio e incentivar a busca de assistência profissional, como a de Médico, a de especialista em saúde mental e a de conselheiro ou assistente social (BRASIL, 2017).

Para isso, é fundamental que sejam intensificadas nos cursos de Ensino Superior a abordagem humanista desse profissional, preparando-o para agir empaticamente diante de um indivíduo em risco de suicídio, que necessita de auxílio para o enfrentamento desse continumm suicida.

A sobrevivência a uma tentativa de suicídio não deve ser entendida como um momento sem riscos, haja vista o período de melhora sequencial após essa tentativa ser considerado um dos mais perigosos e a semana que se segue depois da alta hospitalar é um momento de extrema fragilidade. Além disso, o fator preditivo isolado mais importante é a tentativa prévia de suicídio, que aumenta de 5 a 6 vezes a possibilidade de o indivíduo tentar novamente e, ainda, entre os suicidas é estimado que cerca de metade já houvesse, em seus históricos, alguma tentativa (CFM; ABP, 2014).

De acordo com Christiansen e Jensen (2007), a repetição da tentativa de suicídio e mortalidade após a tentativa estão positivamente associados aos fatores que se relacionam à abordagem terapêutica das doenças mentais. Isso é explicado nos estudos de seguimento de Azcárate-Jiménez et al. (2019), que mostraram, nos seis meses seguintes ao intento suicida, as principais diferenças comparativas entre os que repetiram ou não a tentativa não se relacionaram com apresentação de arrependimento ou com convivência com outras pessoas, mas sim pela gravidade clínica do paciente que, nesse estudo, foi sinalizada pela história de visitas prévias em unidades de emergência psiquiátrica, tratamento de saúde mental ou psicofarmacológico.

Baseado nesse contexto, o presente trabalho trouxe à tona questionamentos acerca do período logo após a tentativa de suicídio. Em uma das perguntas, presente no Quadro 12, foi dada à afirmação de tal momento ser marcado por fragilidade e manutenção do potencial suicida. Quanto a isso, cerca de $90 \%$ dos 134 participantes concordaram com a afirmação. Ao se comparar os cursos, foi verificado que esse percentual de concordância foi apenas abaixo de $80 \%$ entre os acadêmicos de Pedagogia e o restante variou aproximadamente entre $92 \%$ a 95\%. Por outro lado, o índice dos que discordaram dessa fragilidade e risco de reincidência de tentativa foi cerca de $2 \%$ e os que ficaram em dúvida foi de um pouco mais de $5 \%$.

Quadro 12 - A pessoa, no período logo após a tentativa de suicídio, encontra-se fragilizada e mantém-se em risco potencial de suicídio

\begin{tabular}{|l|c|c|c|c|c|c|}
\hline & MED & MT & PD & PS & SS & Total \\
\hline $\begin{array}{l}\text { Concordo } \\
\text { parcialmente }\end{array}$ & 8 & 9 & 3 & 7 & 1 & 28 \\
& $(17,8 \%)$ & $(30,0 \%)$ & $(23,1 \%)$ & $(25,0 \%)$ & $(5,6 \%)$ & $(20,9 \%)$ \\
\hline $\begin{array}{l}\text { Concordo } \\
\text { totalmente }\end{array}$ & 35 & 19 & 7 & 19 & 16 & 96 \\
$(77,8 \%)$ & $(63,3 \%)$ & $(53,8 \%)$ & $(67,9 \%)$ & $(88,9 \%)$ & $(71, \%)$ \\
\hline $\begin{array}{l}\text { Discordo } \\
\text { parcialmente }\end{array}$ & 1 & 0 & 1 & 0 & 1 & 3 \\
Tenho & $1,2 \%)$ & $(0,0 \%)$ & $(7,7 \%)$ & $(0,0 \%)$ & $(5,6 \%)$ & $(2,2 \%)$ \\
\hline dúvida & $(2,2 \%)$ & $(6,7 \%)$ & $(15,4 \%)$ & $(7,1 \%)$ & $(0,0) \%$ & $(5,2 \%)$ \\
\hline Total & 45 & 30 & 13 & 28 & 18 & 134 \\
\hline
\end{tabular}

Fonte: Dados da pesquisa.

Houve também outra questão (Quadro 13), em que se alegou uma situação de incômodo do indivíduo e, portanto, uma tendência a mudar de ideia. Nesse item, pouco menos de $20 \%$ dos participantes concordaram, cerca de $24 \%$ expressaram dúvida e por volta de $57 \%$ manifestaram discordância. A comparação entre os grupos mostrou os acadêmicos de Pedagogia como os que mais concordam com isso e entre todos que discordam, a maioria assinalou que discorda parcialmente. Essa última pergunta gerou diversidade de opiniões, padrão este diferente do apresentado na questão anterior. Diante disso, nota-se que na primeira questão o perfil de respostas, predominantemente, esteve em consonância com o que aponta os dados epidemiológicos e padrão de conduta dos indivíduos, após a tentativa de suicídio.

Enquanto na segunda, houve mais divergência, apesar de como descrito anteriormente, pode haver sim certo arrependimento, descrito no questionário como o sentir incomodado, porém isso não se associa a um menor risco de suicídio. Verifica-se, portanto, a importância de salientar que a prática educativa continuada em saúde, cujo objetivo não é simplesmente o de informar, mas o de possibilitar a transformação do saber, é fundamental para promoção do desenvolvimento da responsabilidade dos indivíduos no cuidado com a saúde (SOUZA; JACOBINA, 2009). 
Quadro 13 - A pessoa, no período logo após a tentativa de suicídio, sente-se incomodada pelo que fez e tende a mudar de ideia.

\begin{tabular}{|c|c|c|c|c|c|c|}
\hline & MED & MT & PD & PS & SS & Total \\
\hline $\begin{array}{l}\text { Concordo } \\
\text { parcialmente }\end{array}$ & $\begin{array}{c}6 \\
(13,0 \%)\end{array}$ & $\begin{array}{c}7 \\
(24,1 \%)\end{array}$ & $\begin{array}{c}4 \\
(30,8 \%)\end{array}$ & $\begin{array}{c}3 \\
(11,1 \%)\end{array}$ & $\begin{array}{c}4 \\
(22,2 \%) \\
\end{array}$ & $\begin{array}{c}24 \\
(18,0 \%) \\
\end{array}$ \\
\hline $\begin{array}{l}\text { Concordo } \\
\text { totalmente }\end{array}$ & $\begin{array}{c}0 \\
(0,0 \%)\end{array}$ & $\begin{array}{c}0 \\
(0,0 \%)\end{array}$ & $\begin{array}{c}0 \\
(0,0 \%)\end{array}$ & $\begin{array}{c}0 \\
(0,0 \%)\end{array}$ & $\begin{array}{c}1 \\
(5,6 \%)\end{array}$ & $\begin{array}{c}1 \\
(0,8 \%)\end{array}$ \\
\hline $\begin{array}{l}\text { Discordo } \\
\text { parcialmente }\end{array}$ & $\begin{array}{c}14 \\
(30,4 \%)\end{array}$ & $\begin{array}{c}14 \\
(48,3 \%)\end{array}$ & $\begin{array}{c}6 \\
(46,2 \%)\end{array}$ & $\begin{array}{c}9 \\
(33,3 \%)\end{array}$ & $\begin{array}{c}5 \\
(27,8 \%)\end{array}$ & $\begin{array}{c}48 \\
(36,1 \%)\end{array}$ \\
\hline $\begin{array}{l}\text { Discordo } \\
\text { totalmente }\end{array}$ & $\begin{array}{c}12 \\
(26,1 \%)\end{array}$ & $\begin{array}{c}3 \\
(10,3 \%)\end{array}$ & $\begin{array}{c}0 \\
(0,0 \%)\end{array}$ & $\begin{array}{c}8 \\
(29,6 \%)\end{array}$ & $\begin{array}{c}5 \\
(27,8 \%)\end{array}$ & $\begin{array}{c}28 \\
(21,1 \%)\end{array}$ \\
\hline $\begin{array}{l}\text { Tenho } \\
\text { dúvida }\end{array}$ & $\begin{array}{c}14 \\
(30,4 \%)\end{array}$ & $\begin{array}{c}5 \\
(17,2 \%)\end{array}$ & $\left(\begin{array}{c}3 \\
(23,1 \%)\end{array}\right.$ & $\begin{array}{c}7 \\
(25,9 \%)\end{array}$ & $\begin{array}{c}3 \\
(16,7 \%)\end{array}$ & $\begin{array}{c}32 \\
(24.1 \%)\end{array}$ \\
\hline Total & 46 & 29 & 13 & 27 & 18 & 133 \\
\hline
\end{tabular}

Fonte: dados da pesquisa.

Outra perspectiva avaliada ainda no contexto do anúncio prévio da tentativa de suicídio associa a influência do ditado popular e o já abordado pronunciamento do desejo de se suicidar e a relação com o fato mais provável. Segundo Figueiredo (2012), o provérbio popular é um símbolo de representatividade do legado das tradições e costumes que resgatam os valores culturais e linguísticos na sociedade, repassados entre sucessivas gerações. Apesar do elevado índice de disseminação, os ditados populares podem se enquadrar como mitos entre os quais se encontra o "quem fala, não faz" que é um perigoso fator de risco no contexto do suicídio (DIAS, 2018). Sobre isso foi questionado, com base nesse provérbio, se a pessoa que realiza ameaças verbais não seria capaz de cometer suicídio. Entre os quase $98 \%$ dos que responderam a essa questão, cerca de $85 \%$ discordam de tal afirmação, como é visto na Quadro 14. Ao comparar os acadêmicos dentro de seus respectivos grupo, verificou-se que os do curso de Pedagogia apresentaram maior taxa de dúvida, enquanto os de Medicina e Serviço Social em mais de $90 \%$ discordaram e os de Matemática, ainda que tenham discordado em aproximadamente $70 \%$, foram os que mais concordaram com a veracidade do dito popular no que tange ao suicídio.

Dessa maneira, é explícito o fato de que as repercussões do provérbio "quem fala, não faz" são sempre negativas, mas entre os entrevistados não houve interferência substancial na compreensão do risco inerente àqueles que expressam o desejo de dar fim à própria vida.

Quadro 14 - A sabedoria popular afirma que "quem fala não faz", logo, quem fala em tirar a própria vida não comete suicídio.

\begin{tabular}{|l|c|c|c|c|c|c|}
\hline & MED & MT & PD & PS & SS & Total \\
\hline $\begin{array}{l}\text { Concordo } \\
\text { parcialmente }\end{array}$ & 1 & 4 & 0 & 0 & 0 & 5 \\
$(2,2 \%)$ & $(13,8 \%)$ & $(0,0 \%)$ & $(0,0 \%)$ & $(0,0 \%)$ & $(3,8 \%)$ \\
\hline $\begin{array}{l}\text { Concordo } \\
\text { totalmente }\end{array}$ & 0 & 1 & 1 & 0 & 0 & 2 \\
$(0,0 \%)$ & $(3,4 \%)$ & $(7,7 \%)$ & $(0,0 \%)$ & $(0,0 \%)$ & $(1,5 \%)$ \\
\hline $\begin{array}{l}\text { Discordo } \\
\text { parcialmente }\end{array}$ & 5 & 8 & 5 & 1 & 3 & 22 \\
\hline $\begin{array}{l}\text { Discordo } \\
\text { totalmente }\end{array}$ & $(84,9 \%)$ & $(27,6 \%)$ & $(38,5 \%)$ & $(3,7 \%)$ & $(16,7 \%)$ & $(16,5 \%)$ \\
\hline $\begin{array}{l}\text { Tenho } \\
\text { dúvida }\end{array}$ & 1 & $44,8 \%)$ & $(30,8 \%)$ & 22 & 14 & $91,5 \%)$ \\
$(72,2 \%)$ & $(10,3 \%)$ & $(23,1 \%)$ & $(14,8 \%)$ & $(5,69,2 \%)$ \\
\hline Total & 46 & 29 & 13 & 27 & 1 & 12 \\
$(9,0 \%)$ & 133 \\
\hline
\end{tabular}

Fonte: dados da pesquisa.

\subsection{Influência da campanha}

Com relação à influência da Campanha constatou-se que:

a) $49,79 \%$ tiveram contato com a campanha e desses: $6,15 \%$ entendem que é desejo de chantagear; $3,08 \%$ entendem que nunca suicidarão e $90,77 \%$ entendem que chegarão a praticar o suicídio. Por outro lado, $52,21 \%$ não tiveram contato com a campanha e desses: $5,63 \%$ entendem que é desejo de chantagear; $7,04 \%$ entendem que nunca suicidarão e 87,32 $\%$ entendem que chegarão a praticar o suicídio. Nesse quesito não há grande diferença entre os que tiveram acesso e os que não tiveram.

b) Em relação à questão da aparente tranquilidade em indicar a decisão de executar o ato de suicídio se tem que entrevistados, que não tiveram acesso às campanhas de conscientização: $35,21 \%$ concordam, $32,4 \%$ discordam e $32,39 \%$ têm dúvida, enquanto entrevistados que tiveram acesso às campanhas de conscientização: 26,16\% concordam, 52,3\% discordam e $21,54 \%$ têm dúvida. Aqui há uma diferença entre os que discordam. Fator esse que é preocupante, tendo em vista que o objetivo da campanha era exatamente o oposto.

c) Diante da questão em que se procurou saber se a pessoa deve receber de atendimento especializado se constatou que entrevistados, que não tiveram acesso às campanhas de conscientização: todos concordam. Por outro lado, entrevistados que tiveram acesso às campanhas de conscientização: $96,88 \%$ concordam, 3,13\% discordam. Isso demonstra que a campanha não está surtindo o efeito esperado.

d) Se a pessoa está agitada é porque está indecisa, os entrevistados que não tiveram acesso às campanhas de conscientização: $46,48 \%$ concordam, $36,62 \%$ discordam, $16,9 \%$ têm dúvida, mas os entrevistados que tiveram acesso às campanhas de conscientização: $32,82 \%$ concordam, $46,88 \%$ discordam, $20,31 \%$ têm dúvida. Novamente, se tem efeito contrário o objetivo da campanha.

e) Deve a pessoa, que anuncia a intenção de cometer suicídio, ter a sua fala ignorada? Entrevistados, que não tiveram acesso às campanhas de conscientização: 2,86\% concordam, 87,15\% discordam, $10 \%$ têm dúvida. Por outro lado, entrevistados que tiveram acesso às campanhas de conscientização: $90,63 \%$ discordam, 9,38\% têm dúvida. Aqui o empate técnico não é favorável à campanha.

f) Essa pessoa é alguém que está sofrendo muito? Entrevistados que não tiveram acesso às campanhas de conscientização: $74,28 \%$ concordam, $21,43 \%$ discordam, $4,29 \%$ têm dúvida. Aqui também há indícios de que mesmo sem o contato com a campanha, há certo padrão de empatia, mas isso não anula a necessária intensificação da campanha.

\section{Conclusão}

Um primeiro ponto a destacar é que a campanha pública de esclarecimento a respeito do trato com a pessoa com tendência suicida ainda não produziu resultados, porém não é possível afirmar nada sobre a sua eficácia ou não. Esperase que um maior destaque possa ter contribuição efetiva. Em alguns aspectos, a sociedade já tem conhecimento sobre esse comportamento, sendo necessário focalizar outros pontos da crise enfrentada por quem tem tendência suicida.

Verificou-se, portanto, que alguns padrões comportamentais saudáveis em relação à prevenção e combate ao suicídio são reflexos do processo de formação acadêmica, em curso dos entrevistados e não propriamente do contato com as campanhas, como observado entre os que não 
tiveram acesso ao material de campanha, que em quase 75\% concorda em haver relação entre tendência suicida e alto nível de sofrimento.

Além disso, mais de $70 \%$ dos que não conheciam a campanha já tinham consciência do sofrimento de quem está prestes a tirar a própria vida. Da mesma forma que $87 \%$ sabem que se deve ouvir e apoiar. A sugestão é que o próximo passo seja orientar como apoiar, como encaminhar e, até mesmo, como identificar. Atividade que pode ser desenvolvida, em sala de aula, por inciativa dos professores ou da coordenação, quiçá da própria Instituição ${ }^{1}$. Esperar que somente as campanhas publicitárias supram essa deficiência é esperar demais.

\section{Referências}

ABP - Associação Brasileira de Psiquiatria; CFM - Conselho Federal de Medicina. Suicídio: informando para prevenir. Brasília: Comissão de Estudos e Prevenção de Suicídio, 2014.

ABP-AssociaçãoBrasileiradePsiquiatria;CFM-ConselhoFederal De Medicina; APAL - Asociación Psiquiátrica da América Latina. Carta aos pais, responsáveis e educadores. 2019. Disponível em: $\quad<$ https://a0e38812-554e-49f8-abbd-a0342f167fe7.filesusr. com/ugd/26b667_c2cb6b1dd8eb482eb535852ee79e8b32.pdf $>$. Acesso em: 21 abr. 2020.

AZCÁRATE-JIMÉNEZ, L. et al. La repetición del intento de suicidio: un estudio de seguimiento. Actas Espanolas Psiquiatria, v.47, n.4, p.127-136, 2019.

Bertolote, J.M.; MEllo-SANTOS, C.; BOteGA, N.J. Detecção do risco de suicídio nos serviços de emergência psiquiátrica. Rev. Bras. Psiquiatr., v.32, p.S87-S95, 2010. doi: https://doi.org/10.1590/S1516-44462010000600005.

BRASIL. Ministério da Saúde. Conselho Nacional de Saúde. Resolução $\mathrm{n}^{\circ} 466$, de 12 de dezembro de 2012. Diretrizes e normas regulamentadoras de pesquisas envolvendo seres humanos. Diário Oficial da União [da] República Federativa do Brasil. 2013 jun 13;150(112 Seção 1):59-62.

BRASIL. Ministério da Saúde. Perfil epidemiológico das tentativas e óbitos por suicídio no Brasil e a rede de atenção à saúde. Boletim Epidemiol., v.48, n.30, 2017.

BRASIL. Ministério da Saúde. Portaria No 354, de 10 de março de 2014. Projeto de Resolução Boas práticas para organização e funcionamento de serviços de urgência e emergência. Brasília: MS, 2014.

CASSORLA, R.M.S. Debate sobre o artigo de Everardo Duarte Nunes. Cadernos de Saúde Pública, Rio de Janeiro, v.14, n.1, p. 28-30, jan. 1998..

CASSORLA, R. Jovens que tentam suicídio e narcisismo destrutivo. Medicina, v.38, n.1, p.45-48, 2005.

CVV - Centro de Valorização da Vida. O movimento. 2019. Disponível em: https://www.setembroamarelo.org.br/omovimento/. Acesso em: 16 abr. 2020.
CHRISTIANSEN, E.; JENSEN, B.F. Risk of repetition of suicide attempt, suicide or all deaths after an episode of attempted suicide: a register-based survival analysis. Australian New Zealand J. Psychiatr., v.41, n.3, p. 257-265, 2007.

DAUDT, A.D. et al. Manejo em emergência do paciente suicida. Portal Regional da BVSL, 2018. Disponível em: http://docs. bvsalud.org/biblioref/2018/04/882736/manejo-em-emergenciado-paciente-suicida.pdf. Acesso em: 21 abr. 2020.

DEL-BEN, C. et al. Emergências psiquiátricas: manejo de agitação psicomotora e avaliação de risco suicida. Medicina, v.50, p.98-112, 2017.

DIAS, P. Setembro Amarelo: suicídio: falar sobre esse problema é importante. Portal UFLA. 2018. Disponível em: < https://ufla.br/ noticias/extensao/12304-suicidio-entenda-porque-e-importantefalar-sobre-esse-problema >. Acesso em: 29 set. 2020.

FIGUEIREDO, G.R. O Gênero Proverbial na Imprensa: usos e funções retóricas. Recife: Universidade Federal de Pernambuco, 2012.

FLEISCHMANN, A. et al. Effectiveness of brief intervention and contact for suicide attempters: a randomized controlled trial in five countries. Bull World Health Organ, 2008. doi: https:// dx.doi.org/10.2471\%2FBLT.07.046995.

MELEIRO, A.M.A.S.; MELLO, C.; WANG, Y. P. Suicídio e tentativa de suicídio. In: LOUZÃ NETO, M.R.; ELKIS, H. (Org.). Psiquiatria Básica. São Paulo: Artmed, 2007. p.475-496.

OMS - Organização Mundial de Saúde. Departamento de saúde mental. Prevenção do suicídio: Manual para Professores e Educadores. Transtornos mentais e comportamentais. Genebra: OMS, 2000.

PRADO, A.S.; PINTO, L.R. Vamos falar sobre suicídio? A prevenção no ambiente escolar. Curitiba: Instituto Federal do Paraná, 2019.

SANTOS, L.A; KIND, L. Integralidade, intersetorialidade e cuidado em saúde: caminhos para se enfrentar o suicídio. Interface, v.24, e190116, 2020.

SADOCK, B.J.; SADOCK, V.A.; RUIZ, P. Compêndio de psiquiatria: ciência do comportamento e psiquiatria clínica. Porto Alegre: Artmed, 2017.

SOUZA, I.P.M.A.; JACOBINA, R.R. Educação em saúde e suas versões na história brasileira. Rev. Baiana Saúde Pública, v.33, n.4, p.618-627, 2009. 2020.

STAVIZKI- JUNIOR, C; VICCARI, E.M. O serviço social no atendimento de emergências psiquiátricas: processos de trabalho de assistentes sociais e residentes no atendimento de pacientes adolescentes com ideação e tentativa de suicídio. Barbarói, v.1, p.113-132, 2019.

WHO - World Health Organization. Multisite intervention study on suicidal behaviours SUPRE-MISS: protocol of SUPRE-MISS. Geneva: WHO, 2002.

WHO - World Health Organization. World health statistics 2019: monitoring health for the SDGs, sustainable development goals. Genebra: WHO, 2019.

\footnotetext{
2 Exemplo dado pela Universidade Federal de Viçosa que desde 2016 desenvolve atividades de extensão sobre o tema, incluindo palestras e outras mobilizações. Disponível em: https://ufla.br/component/search/?searchword=suic\%C3\%ADdio\&searchphrase=all\&Itemid=156.
} 